\title{
Comorbidity of panic disorder and major depressive disorder: effects on platelet alpha $_{2}$ adrenergic receptors
}

Grunhaus LJ, Cameron O, Pande AC, Haskett RF, Hollingsworth PJ, Smith CB. Comorbidity of panic disorder and major depressive disorder: effects on platelet alpha ${ }_{2}$ adrenergic receptors.

Acta Psychiatr Scand 1990: 81: 216-219.

Adrenergic receptor dysregulation has been described as occurring in both major depressive disorder (MDD) and panic disorder. Measurements of platelet alpha ${ }_{2}$ adrenergic receptors in these patients may be confounded by the coexistence or comorbidity of both diagnoses in the same patient. To explore this possibility, we measured platelet alpha ${ }_{2}$ adrenergic receptors $\left({ }^{3} \mathrm{H}\right.$-clonidine and ${ }^{3} \mathrm{H}$-yohimbine binding) in 3 groups of patients (MDD only, panic disorder only, and those showing comorbidity of MDD and panic) and normal controls. Patients with comorbidity of MDD and panic disorder had significantly lower agonist binding $\left({ }^{3} \mathrm{H}\right.$-clonidine $)$.
L. J. Grunhaus', O. Cameron', A. C. Pande ${ }^{1}$, R. F. Haskett ${ }^{1}$, P. J. Hollingsworth ${ }^{2}$, C. B. Smith ${ }^{2}$

Departments of ${ }^{1}$ Psychiatry and ${ }^{2}$ Pharmacology, University of Michigan Medical Center, Ann Arbor, Michigan, USA

Key words: panic disorder; affective disorder; adrenergic receptor; comorbidity

Leon J. Grunhaus, M.D., Department of Psychiatry, University of Michigan Medical Center, D9702, Box 0118, 1500 East Medical Center Drive, Ann Arbor, MI 48109-0118, USA

Accepted for publication August 19, 1989
Adrenergic receptor dysregulation has been proposed as occurring in both major depressive disorder (MDD) and panic disorder. Most of the evidence supporting these hypotheses has been obtained by measuring products of adrenergic receptor activity, i.e., plasma catecholamines, or metabolites of these secretions, i.e., plasma 3-methoxy-4-hydroxyphenylglycol (MHPG). More direct assessment of receptor function in humans is difficult because of the relative inaccessibility of brain tissue. Blood platelets seem to share properties with central neurons (the neuronal model concept of Pletscher (1)), and thus have been used as peripheral markers for receptor activity $(2,3)$. Many studies have measured alpha ${ }_{2}$ adrenergic receptors in platelets of patients with either MDD or panic disorder; unfortunately, results have not been consistent and are difficult to interpret because of methodological differences between the studies (3-5). When alpha ${ }_{2}$ receptor agonists $\left({ }^{3} \mathrm{H}\right.$ clonidine or ${ }^{3} \mathrm{H}$-p-aminoclonidine) are used as ligands on fresh platelet membranes, most studies (6-9), but not all (10) suggest that high-affinity binding sites are increased in patients with MDD; on the other hand, if frozen platelets are used as substrate (11), these differences disappear. When alpha receptor antagonists $\left({ }^{3} \mathrm{H}\right.$-dihydroergocryptine, ${ }^{3} \mathrm{H}$ rauwolscine or ${ }^{3} \mathrm{H}$-yohimbine) are utilized as ligands, the findings are more heterogeneous, with authors reporting either higher $(12-15)$, normal $(8,16-22)$, or lower (23) receptor numbers. In patients with panic disorder, agonist binding $\left({ }^{3} \mathrm{H}\right.$-clonidine $)$ has been reported as normal (24) whereas antagonist binding ( ${ }^{3} \mathrm{H}$-yohimbine or ${ }^{3} \mathrm{H}$-rauwolscine) has been observed as either lower $(24,25)$ than controls or not significantly different $(26,27)$.

A very relevant factor in assay variability is diagnostic heterogeneity (2). This may be particularly important if the diagnostic heterogeneity is a reflection of underlying pathophysiology. Recent studies suggest that when MDD and panic disorder occur together in the same patient (comorbidity), a more severe disorder may be present, possibly reflecting combined diathesis $(28,29)$. Some support for this hypothesis has emerged from studies of sleep electroencephalographic changes and urinary MHPG in patients with comorbidity of MDD and panic disorder compared with patients with MDD alone. Grunhaus et al. (30) and Dube et al. (31) reported that sleep electroencephalography recordings in patients with comorbidity of MDD and panic disorder were significantly different from those of MDD patients without comorbidity features, even though both groups meet the Research Diagnostic Criteria for MDD endogenous subtype. The comorbidity groups had less of an endogenous profile (higher REM latencies and less REM densities) in the sleep polysomnography recording. Garvey et al. (32) measured urinary MHPG in patients with MDD and subdivided them according to the presence of panic attacks, and found that those with 
MDD and panic (comorbidity group) had significantly higher excretion of urinary MHPG.

To explore whether comorbidity of MDD and panic disorder is a factor in platelet alpha ${ }_{2}$ adrenergic receptor variability, we compared 3 groups of patients (those with MDD alone, those with comorbidity of MDD and panic disorder and those with panic disorder alone) with normal controls. Our findings suggest that platelet alpha $_{2}$ adrenergic receptors are significantly lower in patients with comorbidity of MDD and panic disorder.

\section{Material and methods}

Twenty-seven patients from the Depression and Anxiety Disorders Programs of the Psychiatry Department of the University of Michigan were recruited for this study. In order to be included, patients had to meet DSM-III diagnostic criteria for either MDD or panic disorder for the index episode. Patients with panic disorder were required to have had at least 1 panic attack per week during the preceding 4 weeks. Patients with MDD were required to have scored 15 or more points in the 17-item Hamilton Rating Scale for Depression (HRSD) (33). The evaluation process included diagnostic interviews with senior clinicians for consensus diagnosis and a comprehensive physical examination and thorough laboratory work-up to rule out possible illness. For 14 days prior to withdrawal of samples, patients and controls were kept free of all medications, including benzodiazepines, alcohol, street drugs, and any medication that could affect adrenergic receptors; drug-free status was verified with a urine drug screen that preceded blood sampling by 3 days. During the diagnostic interviews, patients with MDD were carefully questioned for the presence of panic attacks during the current episode of illness; those having panic attacks of sufficient severity and frequency to meet the criteria for panic disorder were later subcategorized as patients with comorbidity of MDD and panic disorder. Thus, participating patients were categorized into 3 groups: patients with MDD only (those never meeting criteria for anxiety diagnosis; $n=14$ ); patients with panic disorder only (these never meeting criteria for a depression diagnosis; $n=6$ ), and patients with comorbidity of MDD and panic disorder (those meeting criteria for both disorders; $n=7$ ).

Fifteen volunteers with normal physical exam and laboratory studies were included as the control group. The psychiatric assessment of the normal volunteers was done using the Schedule for Affective Disorders and Schizophrenia (SADS) (34) and HRSD. Any volunteer with personal or first-degree family history of any psychiatric disorder or an
HRSD > 5 was not accepted for the study. The rejection rate for normal volunteers was approximately $30 \%$.

The research protocol was approved by the institutional review board in charge of supervising research in humans, and all subjects signed a written informed consent for participation in the protocol. All subjects fasted and remained supine after midnight preceding blood withdrawal. An antecubital catheter was inserted at 0730 and baseline samples were withdrawn $1 \mathrm{~h}$ later.

Controls were recruited with an attempt to stratify according to the age of the patients. Mean age was $34.4 \pm 11.6$ years for MDD patients, 31.1 \pm 6.9 years for panic disorder patients and $34.3 \pm 6.9$ years for the controls $(F=1.1$; NS). No sex differences were found between the groups.

The platelet alpha $a_{2}$ adrenergic receptor binding assay has been described in detail elsewhere $(6,8)$. Briefly, immediately after withdrawal, blood was mixed with acid-citrate-dextrose anticoagulant buffer. Platelets were isolated, washed, and lysed, and platelet membranes were isolated. Specific binding of tritiated yohimbine or tritiated clonidine to platelet membranes was determined on fresh platelet membranes. Specific binding (total binding minus nonspecific binding) was approximately $85 \%$ for tritiated clonidine and $90 \%$ for tritiated yohimbine. A computerized program (35) that utilizes Scatchard (36) and Hill (37) transformations was used to develop preliminary estimates of the apparent dissociation contents (KD) and the maximum binding sites $\left(B_{\max }\right)$ for the 2 ligands. Final values for the 2 binding parameters were estimated by use of the nonlinear regression analysis program devised by Munson \& Rodbard (38). Assays were performed by individuals blind to patient diagnosis.

Statistical comparisons included a one-way analysis of variance with post-hoc comparisons when significant differences occurred.

\section{Results}

To explore our assumptions regarding the relevance of diagnostic heterogeneity, we first analyzed the results of the platelet receptor assay using the traditional DSM-III categories of MDD and panic disorder (Table 1A) and later separated from the MDD groups the patients with comorbidity (Table 1B).

Using the traditional DSM-III groups, no differences in receptor numbers $\left(B_{\max }\right)$ and dissociation constants $\left(\mathrm{K}_{\mathrm{d}}\right)$ as measured with ${ }^{3} \mathrm{H}$-clonidine (agonist) and ${ }^{3} \mathrm{H}$-yohimbine (antagonist) binding between the groups were detected between patients and controls (see Table 1A for actual values). When patients were separated according to the comorbidity 
Table 1. Platelet alpha ${ }_{2}$ adrenergic receptor values in patients with MDD, panic disorder, comorbidity of MDD and panic disorder and normal controls $\left(_{\max }\right.$ expressed as $\mathrm{fmol} / \mathrm{mg}$ protein)

A: according to DSM-ill diagnostic groups

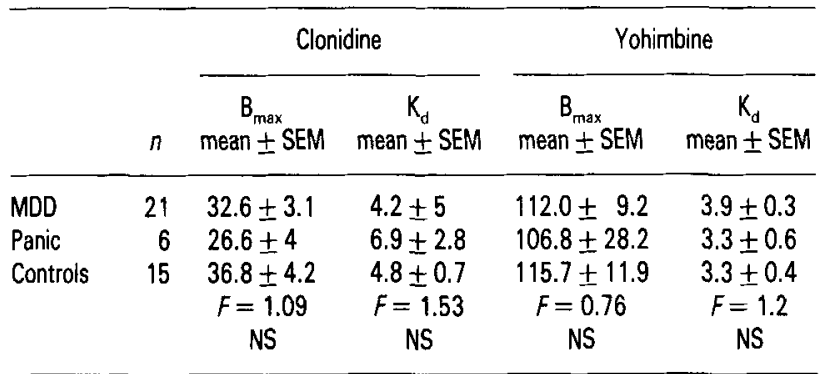

B: according to comorbidity groups

\begin{tabular}{lrcccc}
\hline MDD & 14 & $38.6 \pm 3.5$ & $4.1 \pm 0.5$ & $118.4 \pm 11.5$ & $3.6 \pm 0.4$ \\
MOD and & & & & & \\
$\quad$ panic & 7 & $20.7 \pm 3.0$ & $3.9 \pm 0.2$ & $107.5 \pm 18.7$ & $4.7 \pm 0.7$ \\
Panic & 6 & $26.6 \pm 3.9$ & $6.9 \pm 2.7$ & $106.8 \pm 28.1$ & $3.3 \pm 0.6$ \\
Controls & 15 & $36.8 \pm 4.3$ & $4.8 \pm 0.7$ & $115.7 \pm 11.9$ & $3.3 \pm 0.4$ \\
& & $F=3.62^{*}$ & $F=1.23$ & $F=0.12$ & $F=1.72$ \\
& & & NS & NS & NS \\
\hline
\end{tabular}

${ }^{*} P<0.02 ;$ MDD and panic vs controls: $P<0.01 ;$ MDD and panic vs MDD: $P<0.01$.

group (Table 1B), significant differences appeared. $\mathrm{B}_{\max }$ for ${ }^{3} \mathrm{H}$-clonidine binding in patients with comorbidity of MDD and panic disorder is significantly lower than in controls and MDD patients (MDD: $38.6 \pm 3.5$, comorbidity group $20.7 \pm 3.0$, panic disorder group $26.6 \pm 3.9$, controls $36.8 \pm 4.3$ (fmol $/ \mathrm{mg}$ protein) $; F=3.62 ; P=0.02$ ). Interestingly, $B_{\max }$ values for ${ }^{3} \mathrm{H}$-clonidine showed a trend toward being significantly lower in the panic disorder group than in the MDD group, suggesting that the lower agonist binding may be a feature of the panic groups. ${ }^{3} \mathrm{H}$-yohimbine binding appears to be lower in the panic groups (NS). Kd for agonist and antagonist binding were not significantly different between the groups.

\section{Discussion}

Our results suggest that alpha $\mathrm{a}_{2}$ adrenergic receptors in platelets of patients who show comorbidity of MDD and panic disorder are significantly lower than those measured in normal controls or patients with MDD alone. These findings are of interest and support our initial assumption that patients with comorbidity of depression and panic are different from a pathophysiological perspective from patients with MDD alone. They also provide support to the suggestions that patients with comorbidity of MDD and panic disorder differ from patients with MDD alone on clinical and biological parameters. Patients with the combined diagnoses are likely to exhibit more severe psychopathology $(28,30,39-41)$, greater number of affected relatives $(28,42)$, worse treat- ment outcome $(39,43)$, and greater lifelong impairment $(41,43)$.

These observations should be considered preliminary for several reasons:

- The number of patients studied is relatively small, and this may account for the differences observed between this study and previous reports from our group showing higher ${ }^{3} \mathrm{H}$-clonidine binding in MDD patients (7) and lower ${ }^{3} \mathrm{H}$-yohimbine binding in panic disorder patients (24).

- More direct measures of receptor function were not incorporated into the paradigm studied.

- The relationship between plasma catecholamines and receptor numbers $\left(\mathrm{B}_{\max }\right)$ was not explored; it is possible that the lower $B_{\max }$ observed in the population with panic attacks is associated with higher levels of circulating catecholamines.

A heightened adrenergic tone has been suggested to occur in patients with panic disorder $(24,44-56)$, in melancholic patients (47) and in patients with MDD with panic attacks (31). It is possible that adrenergic dysregulation is a feature common to patients with panic attacks regardless of the diagnosis. The findings we are reporting suggest that, in studies of alpha $_{2}$ adrenergic receptor function in MDD and panic disorder, the presence of comorbidity of these conditions may confound the results of biological studies.

The question of peripheral-central interactions must also be clarified. Charney et al. (44-46) have suggested that hyperactive presynaptic alpha $\mathrm{a}_{2}$ adrenergic receptors at the level of the locus coeruleus are a feature of panic disorder patients. This central upregulation of alpha ${ }_{2}$ receptor could be conducive to peripheral downregulation, possibly through higher circulating catecholamine levels. Whether central upregulation and peripheral downregulation of alpha $\mathrm{a}_{2}$ receptors is a feature common to patients with high circulating catecholamines is an interesting possibility yet to be explored.

It is unclear whether the differences we describe represent true biological differences. Most certainly, replication and extension of these findings is necessary. If supported, it may suggest that lower platelet alpha ${ }_{2}$ adrenergic receptors, as measured by agonist binding, are a feature more closely related to patients who show comorbidity of panic and MDD. Most certainly, combining studies of receptor function with actual receptor measurements is a necessary future step in clarifying this interesting question.

\section{References}

1. Pletscher A, Affolter $H$, Cesura $M$ et al. Blood platelets as models for neurons: similarities of the 5-hydroxytryptamine systems. In: SCHLOSSBERGER HG, Kochem W, LiNZEN B et al., eds. Progress in tryptophan and serotonin research, Berlin: W \& Co, 1984: 231-239. 
2. WIRZ-JUSTICE A. Platelet research in psychiatry. Experientia 1988: 44: 145-152.

3. KafKa MS, PaUL SM. Platelet alpha ${ }_{2}$ adrenergic receptors in depression. Arch Gen Psychiatry 1986: 43: 91-95.

4. Katona ClE, Theodorou AE, Horton RW. Alpha adrenoreceptors in depression. Psychiatr Dev 1987: 2: 129.

5. GARCIA-SEVILlA JA. The platelet alpha $a_{2}$ adrenoreceptor as a potential biological marker in depression. $\mathrm{Br} \mathrm{J}$ Psychiatry 1989: 154 (suppl 4): 67-72.

6. Garcia-Sevilla JA, Guimon J, Garcia-Vallejo $P$ et al. Biochemical and functional evidence of supersensitive platelet alpha $a_{2}$ adrenoceptors in major affective disorder. Arch Gen Psychiatry 1986: 43: 51.

7. Garcia-Sevilla JA, Zis AP, Hollingsworth PJ et al. Platelet alpha $_{2}$ adrenergic receptors in major depressive disorder Arch Gen Psychiatry 1981: 38: 1327-1333.

8. Smith CB, Hollingsworth PJ, Garcia-Sevilla JA et al. Platelet alpha $a_{2}$ adrenoreceptors are decreased in number after antidepressant therapy. Prog Neuropsychopharmacol Biol Psychiatry 1983: 7: 241-247.

9. Doyle MC, George AJ, Ravindram AV et al. Platelet alpha $_{2}$ adrenoreceptor binding in elderly depressed patients. Am J Psychiatry 1985: 142: 1489-1490.

10. Carstens ME, Engelbrecht AH, Russell VA et al. Alpha $_{2}$ adrenoceptor levels on platelets of patients with major depressive disorder. Psychiatry Res 1986: 18: 321-331.

11. Georgotas A, Schweitzer J, McCue R et al. Clinical and treatment effects on ${ }^{3} \mathrm{H}$-clonidine and ${ }^{3} \mathrm{H}$-imipramine binding in elderly depressed patients. Life Sc 1987: 40: 2137-2143.

12. KaFKa MS, VAN KaMMEN DP, KLEINMAN JE et al. Alpha adrenergic function in schizophrenia, affective disorders and some neurological diseases. Commun Psychopharmacol 1980: 4: 477-486.

13. Kafka MS, Nurnberger JL, Siever LJ et al. Alpha adrenergic receptor function in patients with unipolar and bipolar affective disorders. J Affective Disord 1986: 10: 163-169.

14. Healy D, Carney PA, Leonard BE. Monoamine-related markers of depression. J Psychiatry Res 1983: 17: 251-260.

15. Siever LJ, KafKa MS, TARgum $S$ et al. Platelet alphaadrenergic bindings and biochemical responsiveness in depressed patients and controls. Psychiatry Res 1984: 11: 287-302.

16. Dajgui M, Meltzer HY, Tong $C$ et al. Alpha adrenergic receptors in platelet membranes of depressed patients. Life Sci 1981: 29: 2059-2064.

17. Stahl SM, Lemoine PM, Ciaranello RD et al. Platelet alpha $_{2}$ adrenergic receptor sensitivity in major depressive disorder. Psychiatry Res 1983: 10: 157-164.

18. Pimoule C, Briley MS, Gay $\mathrm{CH}$ et al. ${ }^{3} \mathrm{H}$-rauwolscine binding in platelets from depressed patients and healthy volunteers. Psychopharmacology 1983: 79: 308-312.

19. Siever LJ, KAFKA MS, INSEL RR et al. Effect of long-term administration of clorgyline on human platelet alphaadrenergic receptor binding and platelet cyclic-AMP responses. Psychiatry Res 1983: 9: 37-44.

20. Campbell IC, MCKernan RM, Checkely SA et al. Characterization of platelet alpha $\mathrm{a}_{2}$ adrenoceptors and measurement in control and depressed subjects. Psychiatry Res 1985: 14: 17-31.

21. Braddock L, Cowen PJ, Elliot JM et al. Binding of yohimbine and imipramine to platelets in depressed subjects. Psychol Med 1986: 16: 765-773.

22. Wolfe N, COHEN BM, GelenBerg AJ. Alpha 2 adrenergic receptors in platelets membranes of depressed patients. Psychiatry Res 1987: 20: 107-116.

23. WoOd K, SWADE C, CopPEN A. Platelet alpha adrenergic receptors in depression. Acta Pharmacol Toxicol 1985: 56 (suppl 1): 203-211.

24. Cameron OG, Smith CB, Hollingsworth PL et al. Platelet alpha $\mathrm{a}_{2}$ adrenergic receptor binding and plasma catecholamines. Arch Gen Psychiatry 1984: 41: 1144-1148.

25. Albus NA, BONDY B, ACKENHEIL NA. Adrenergic receptors on blood cells: relation to the pathophysiology of anxiety. Clinical Neuropharmacol 1986: 9 (S): 359-361.

26. NuTT DJ, Fraser S. Platelet binding studies in panic disorder. J Affective Disord 1987: 12: 7-11.

27. Norman TR, KImber NM, JUDD FK et al. Platelet ${ }^{3} \mathrm{H}$-rauwolscine binding in patients with panic attacks. Psychiatry Res 1987: 22: 43-48.

28. Leckman JF, Weissman MM, Merikangas KR et al. Panic disorder and major depression. Arch Gen Psychiatry 1983: 40: 1055-1060.

29. Grunhaus L. Simultaneous panic disorder and major depressive disorder: clinical and psychobiological characteristics. Am J Psychiatry 1988: 145: 1214-1221.

30. Grunhaus L, Rabin D, Harel Y et al. Simultaneous panic and depressive disorders: clinical and sleep-EEG correlates. Psychiatry Res 1986: 17: 251.

31. DUbe S, Jones DA, BeLl $\mathbf{J}$ et al. Interface of panic and depression. Psychiatry Res 1986: 19: 119.

32. Garvey MJ, Tollefson GD, Orsulak PJ. Elevations of urinary MHPG in depressed patients with panic attacks. Psychiatry Res 1987: 20: 183.

33. HAmilton M. A rating scale for depression. J Neurol Neurosurg Psychiatry 1960: 23: 56.

34. SPITZER RL, ENDICOTT J. Schedule for affective disorders and schizophrenia. New York: New York Biometrics Research Division, New York State Psychiatric Institute, 1975.

35. MCPherson GS. A practical computer-based approach to the analysis of radioligand experiments. Comput Prog Biomed 1983: 17: 107-114.

36. SCATChARD G. The attractions of proteins for small molecules and ions. Ann NY Acad Sci 1949: 51: 660-672.

37. HILL AV. The possible effects of the aggregation of the molecules of hemoglobin on its dissociation curves. J Physiol 1910: 40: 4-8.

38. MUNSON PJ, RODBARD D. LIGAND: a versatile computerized approach for characterization of ligand-binding systems. Anal Biochem 1980: 107: 220-239.

39. Grunhaus L, Rabin D, Greden JF. Simultaneous panic and depressive disorders: response to antidepressant treatments. J Clin Psychiatry 1986: 47: 4.

40. Dealy, RS, Ishiki DM, AVery DH et al. Secondary depression in anxiety disorders. Compr Psychiatry 1981: 22: 612.

41. Breier A, Charner DS, Heninger GR. Major depression in patients with agoraphobia and panic disorder. Arch Gen Psychiatry 1984: 41: 1129-1135.

42. Weissman MM, Leckman JF, Merikangas KR et al. Depression and anxiety disorders in parents and children. Arch Gen Psychiatry 1984: 41: 845.

43. Van Valkenburg CH, Akiskal HS, Puzantian V et al. Anxious depressions. J Affective Disord 1984: 6: 67.

44. ChaRNeY DS, HeNINGER GR. Noradrenergic function and the mechanism of action of antianxiety treatment. Arch Gen Psychiatry 1985: 42: 458.

45. ChARNEY DS, HENINGER GR. Noradrenergic function and the mechanism of action of antianxiety treatment. Arch Gen Psychiatry 1985: 42: 473.

46. Charney DS, Heninger GR, Breier A. Noradrenergic function in panic anxiety. Arch Gen Psychiatry 1984: 41: 751.

47. Roy A, Pickar D, Linnoila M et al. Plasma norepinephrine levels in affective disorders. Arch Gen Psychiatry 1985: 42: 1181-1185. 